\title{
Institutional delivery service utilization and associated factors among child bearing age women in Goba Woreda, Ethiopia
}

\author{
Daniel Bogale Odo ${ }^{1,}$, , Desalegn Markos Shifti \\ ${ }^{1}$ Department of Public Health, College of Medicine and Health Sciences, Madawalabu University, Bale Goba, Ethiopia \\ ${ }^{2}$ Department of Nursing, College of Medicine and Health Sciences, Madawalabu University, Bale Goba, Ethiopia
}

Email address:

dbogale386@gmail.com (D. Bogale),desalegnmarkos@gmail.com (D. Markos)

\section{To cite this article:}

Daniel Bogale Odo, Desalegn Markos Shifti. Institutional Delivery Service Utilization and Associated Factors among Child Bearing Age Women in Goba Woreda, Ethiopia. Journal of Gynecology and Obstetrics. Vol. 2, No. 4, 2014, pp. 63-70.

doi: $10.11648 /$ j.jgo.20140204.14

\begin{abstract}
In despite of skilled delivery is one of the most tracked Millennium Development Goal indicators, the proportion of births attended by skilled health personnel in Ethiopia is very low. This study aimed at assessing level of institutional delivery service utilization and associated factors among mothers who gave birth during the last twelve months prior to this study. A community based cross sectional study design which is supplemented by qualitative method was conducted on April 2013 in Goba Woreda. One urban and 8 rural smallest administrative unit (kebele) was selected using simple random sampling technique. Then, mothers were selected systematically after 580 study subjects were proportionally allocated to each kebele. Qualitative data were collected through focus group discussions (FGDs). Data were entered and analyzed using SPSS version 16.0. Frequencies, binary and multiple logistic regression analysis were done. The study indicated that 264 (47\%) of the mothers delivered in health facilities. The common reasons for health facilities delivery were seeking better service (80.2\%) and told to deliver on health facility by health professionals during Anti Natal Care follow up (36.1\%). As compared to rural residents, urban residents were 3.6 times more likely to deliver on health facility ( $\mathrm{AOR}=3.6$ and $95 \% \mathrm{CI}=1.86,7.13)$, Anti Natal Care visit during last pregnancy $(\mathrm{AOR}=2.7$ and $95 \% \mathrm{CI}=1.42,5.24)$ and maternal education level $(\mathrm{AOR}=3.1$ and $95 \% \mathrm{CI}=1.41,6.82)$ had positive significant associations with institutional delivery service utilization. As compared to government strategy, institutional delivery service utilization was lower in the study area. Place of esidence, Anti Natal Care visit and maternal educational level were found to be associated with institutional delivery service utilization. Strategies with focus on increasing Anti Natal Care uptake and increasing maternal and their partners' educational level help to increase health facility delivery service utilization.
\end{abstract}

Keywords: Institutional delivery, Goba woreda, Oromia region, Ethiopia

\section{Introduction}

Globally, 287,000 mothers die from complications of pregnancy and childbirth. Developing countries continue to account for $99 \%$ of the total maternal deaths. Of these estimated deaths, sub-Saharan Africa and South Asia accounted for $87 \%$ of the global maternal deaths $[1,2]$. Ethiopia was one of the six countries which account more than $50 \%$ of all maternal deaths in 2008 [3]. The proportion of deaths due to Post Partum Hemorrhage (PPH) that occurred in facilities is most likely due to the fact that over $90 \%$ of births take place at home, and women with $\mathrm{PPH}$ may not be arriving at a health facility in time [4]. The safe motherhood initiative strongly emphasizes ensuring the availability and accessibility of skilled care during pregnancy and childbirth, of which institutional delivery is one element. Hence, an important component in the effort to reduce the health risks of mothers and children is to increase the proportion of babies delivered in a safe and clean environment and under the supervision of health professionals[2,5].

However, in Ethiopia, the proportion of births attended by skilled personnel in health institution is increased in a very slow fashion in the course of five years. The majority 
of Ethiopian women give birth at home without skilled attendants [4]. Further, as reported in the 2005 Ethiopian Demographic and Health Survey (EDHS), the majority of births at home take place in poor hygienic conditions, while only 6 percent were in a health facility and are assisted by trained personnel [5]. There is no as such significant difference in proportions of institutional delivery service utilization between EDHS 2005 and 2011. Similarly, maternal mortality and morbidity levels for Ethiopia are among the highest in the world. Ethiopian maternal mortality ratio currently is 676 per 100,000 live births which is the highest in the world $[5,6]$.

Despite the uniformity in programme design throughout the country, there is considerable regional variation in the utilization of health institutions for delivery and other maternal health services. The percentage of births delivered in health facility ranges from less than 10 percent in Southern Nation Nationality and People of Ethiopia, Affar, Oromia, Somalia, and Benishangul-Gumuz regions to 82 percent in Addis Ababa city [6]. In despite of skilled delivery is one of the most tracked Millennium Development Goals (MDG) indicators, the proportion of births attended by skilled health personnel in Ethiopia is very low [7]. This is revealed by some of the studies conducted on different settings of the country in different times.

Community based study conducted in Munesa woreda, Oromia regional state showed that only 105 (12.3\%) mothers gave birth at health facilities and the vast majority $(87.7 \%)$ delivered at home [8]. As indicated by another community based study conducted in Woldia woreda, Amhara regional state, among 471 respondents, 227 (48.3\%) gave their last birth in health institutions and $243(51.7 \%)$ gave birth at home [9]. Similarly, the study conducted in Dodota woreda revealed that out of the 506 respondents only $92(18.2 \%)$ gave birth to their last child at health facility where as $414(81.8 \%)$ gave birth for their last child at home [10].

The likelihood of giving birth in health institution depends on many factors. Some of these factors are: residential area, availability and quality of health services, social factors such as being illiterate, lack of access to information, having poor knowledge about obstetric complications and delay in starting first ANC visit [7, 11]. Delivery in a health facility is more common among mothers age 20-34, mothers who had at least four ANC visits, and highly educated mothers and mothers in the highest wealth quintiles. Urban births are notably more likely than rural births to be delivered in a health facility (50 percent versus 4 percent) [6].

Institutional delivery service utilization in Oromia region was about $8 \%$ in EDHS 2011 which in turn was lower than the national level [6]. Assessing the factors affecting institutional delivery service utilization in the study area is very important to improve maternity services and thereby reduce maternal and infant deaths. Hence, this study was conducted to determine the status of istitutional delivery service utilization and associated factors in Goba woreda, Oromia Regional State, Ethiopia.

\section{Methods}

\subsection{Study Design and Setting}

Community based cross sectional study design which is supplemented by qualitative study was employed in Goba woreda, Bale zone Ethiopia during April, 2013. Currently, the district has 24 rural and 2 urban kebeles. The estimated total number of women of reproductive age and pregnant women in the woreda (both Rural and Urban) is 16,277 and 2725 respectively. A total of 43 health institutions were available in the woreda [12].

\subsection{Sample Size Determination and Sampling Technique}

Childbearing women who gave birth in the last 12 months in the woreda, regardless of their birth outcome, were included in the sample. The required sample size of eligible mothers for the study was determined using single population proportion formula. The following assumptions were made while calculating the sample size. Ninety five percent confidence level $(95 \% \mathrm{CI})$ of obtaining mothers who gave birth at the health institutions from the population within $5 \%$ margin of error and expecting a $10 \%$ non response rate, the final sample size was calculated to be 580 . One urban and 8 rural kebeles were selected by using simple random sampling technique. Census was carried out in the selected kebeles to identify mothers who gave birth in the last one year prior to the survey. Then, proportional distribution of the sample size for each selected kebeles was done. Finally, mothers were selected by systematic random sampling method. Convenient sampling for FGD was employed. This method was employed because mothers in that specific kebele are expected to be homogenous in many ways. Due to this, easily accessible mothers were selected. Those women who have given birth in the last 12 months, resident in the area for at least 6 month and available during data collection period were included. Four FGD having an average of 8 participants were employed. Out of the four FGDs, one was conducted in Urban and the remaining three FGD were conducted in rural kebeles.

\subsection{Data Collection Procedure}

\subsubsection{For Quantitative Part}

A structured questionnaire developed in English in such a way that it includes all the relevant variables to meet the objective of the study. An individual who had very good knowledge of local language (Afan Oromo) translated the English version questionnaire to local language for better understandability of the tool by enumerators and respondents. Another individual with similar ability translated the tool from Afan Oromo language back to English version to check for its original meaning. Then, the tool was pretested on $5 \%$ similar population in Robe found 
at $14 \mathrm{Km}$ from the actual study setting. Eight diploma Nurses who were fluent in speaking local language were involved in the data collection. Two Bachelor of Science degree (BSc) holder health professionals were recruited as supervisors. All data collectors and supervisors were trained for two days on data collection process based on the guide that was developed by principal investigator for data collectors. The principal investigators and the supervisors strictly followed the overall activities for each activity on daily base to ensure the completeness of questionnaire, to give further clarification and support for data collectors.

\subsubsection{For Qualitative Data}

Homogeneous convenient sampling was carried out to select discussants for focus group discussion (FGD). Four FGD having participant that ranges from 6-12 were conducted. Each session took a time span of one to one and half hours. The groups were made homogeneous in terms of social class, and age. This helped the participants to talk freely whatever they know. Settings were arranged with privacy for participants, comfortable situation (location), avoiding noisy areas, non-threatening environment and easily accessible location. Probing questions and transition approaches were used to introduce new ideas starting from general non-threatening to specific topics of interest.

\subsection{Data Quality Control}

A safe motherhood questionnaire developed by the Maternal and Neonatal Program of JHPIEGO, an affiliate of John Hopkins University was adopted and used [13]. The questionnaire was translated from English to Afan Oromo. It was pre-tested on $5 \%$ of the total sample size in Robe town and necessary adjustment was made before it is used for actual data collection. After pre-test, Cronbatch's Alpha was calculated by using Statistical Package for Social Sciences (SPSS) window version 16.0 to test internal consistency (reliability) of the items and value greater than 0.7 was considered as reliable. In addition to this, content validity was cross checked by maternal and reproductive health expert. Data collectors and supervisors were trained for three days (including practical sessions) on the study instrument and data collection procedure.

\subsection{Data Processing and Analysis}

\subsubsection{For Quantitative Data}

The data were checked for completeness and consistencies. Then, it was cleaned, coded and entered in to computer using SPSS windows version 16.0. Descriptive statistics was computed to determine the institutional delivery service utilization. Additionally, bivariate and multivariate analyses were carried out to examine the existence of relationship between the outcome variable and selected determinant factors. Variables having P-value less than 0.05 on binary logistic regression were the candidate for multiple logistic regressions. Statistical significance was declared at $\mathrm{P} \leq 0.05$.

\subsubsection{For Qualitative Data}

Data were transcribed into English text by the principal investigator by replaying the recorded interview. Different ideas in the text were merged in their thematic areas and a thematic framework analysis was employed manually. Then, result was presented in narration by triangulating the quantitative findings.

\subsection{Ethical Consideration}

The proposal was approved by Ethical Review Committee of College of Medicine and health sciences of Madawalabu University. Furthermore, letter of permission was obtained from Bale Zone health department and from Goba Woreda administrative and health offices. Verbal consent was obtained from the study subjects after they were informed about objectives and procedures of the study and their right to refuse participation any time they want was assured. For this very purpose, a one page consent letter was attached as a cover page of each questionnaire stating about the general objective of the study and issues of confidentiality which was discussed by the data collectors before proceeding with the interview.

\section{Result}

\subsection{Socio-Demographic Characteristics of Respondents}

Out of the total 580 mothers who were planned for the study, 562 were successfully interviewed yielding the response rate of $97 \%$.

The mean age of the study subjects was $26.6(\mathrm{SD} \pm 5.96)$. Muslim and Orthodox Tewahido were found as a dominant religion each accounting 49.1\%. Most participants, 266 $(47.3 \%)$, reported that they were educated up to primary school and about thirty percent were attend secondary and above educational level. Four hundred ten $(73 \%)$ of the respondents were ethnically Oromo, followed by Amhara; 139 (24.7\%). The vast majority, (85.2), of respondent were house wife. Regarding marital status of the respondents, $531(94.5 \%)$ was married. The mean family size (only mother, and father with their children living in a house during the study period) and mean of the estimated income of the participants were $5.01(\mathrm{SD} \pm 2.05)$ and $1267.86(\mathrm{SD} \pm$ $1298.729)$ respectively. Nearly half, $(47.3 \%)$, of the study subjects' husband were educated to the primary level (table $1)$.

Table 1. Socio-demographic characteristics of the respondents, Goba Woreda, Oromia region, South-East Ethiopia, April 2013

\begin{tabular}{lcc}
\hline Variable & Frequency & Percent \\
\hline Residence & & \\
Urban & 116 & 20.6 \\
Rural & 446 & 79.4 \\
Age & & \\
$\leq 20$ & 94 & 16.7 \\
\hline
\end{tabular}




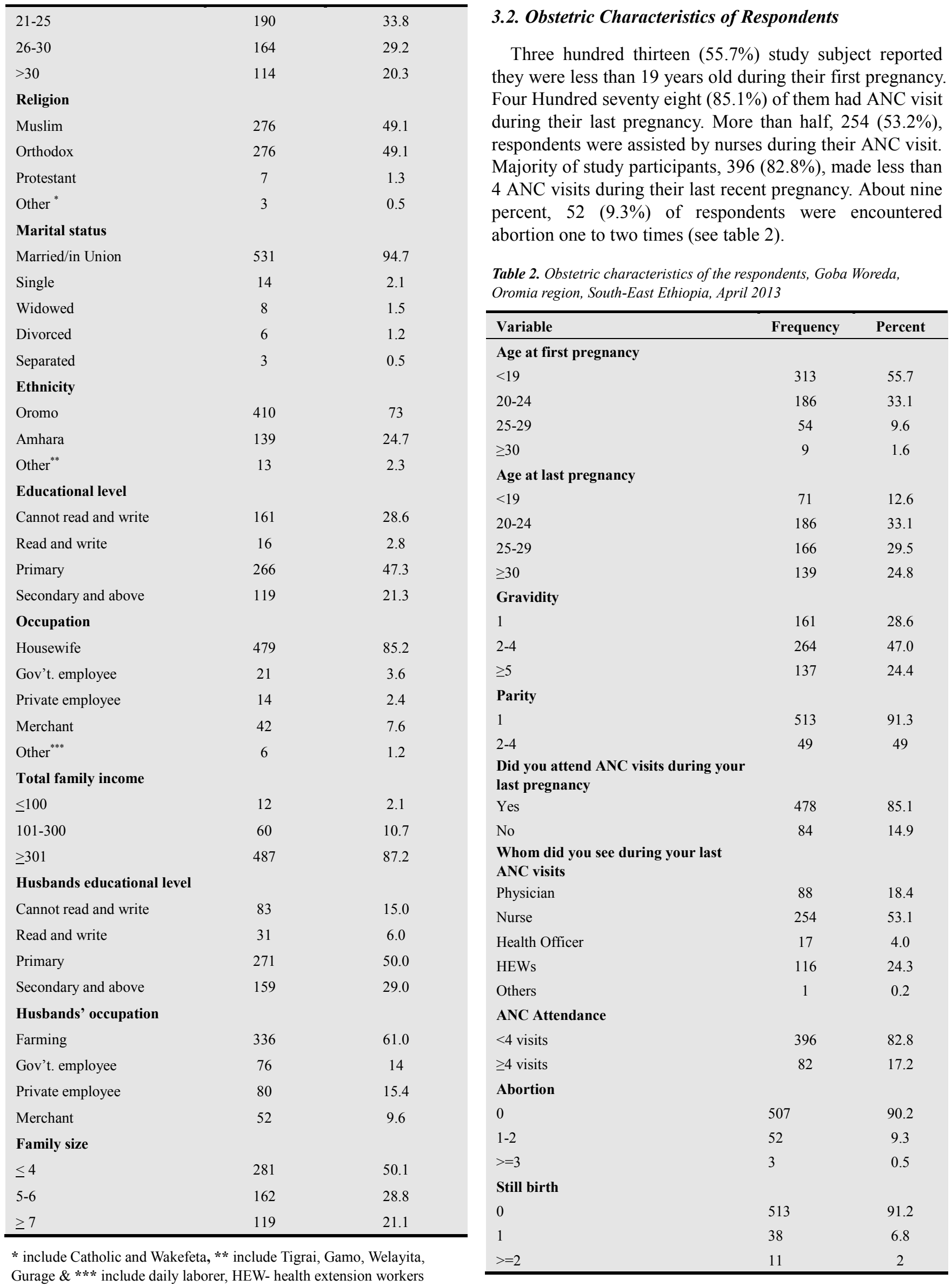




\subsection{Institutional Delivery Service Utilization}

Of the total respondents, only 264 (47\%) of them gave birth at health facilities and the rest, 298 (53\%), delivered at home. The study subjects gave different reasons for their preference to deliver at home. Out of those mothers who delivered at home, $250(83.9 \%)$ and $111(37.2 \%)$ of them reported that their labor was smooth and short and previous home delivery had no problem respectively. Among those mothers who delivered at health facilities, the reasons for delivery on health facilities included; health facility was near to them, to get better service, previous delivery on health facility had better outcome and they told to deliver at health facilities (table 3).

One of the focus group discussants said that, "I gave birth in my home because I was not ready at all. Even if I had planned to give birth in health institution, my labor was very short. You know, it is impossible to stop labor once it is initiated so it hindered me arriving health facility?" Another grade 9 education completed FGD participant said that, “... labor and over flow of river are similar sudden events; you cannot plan them. I think, this is why most females fail to achieve their plan...."

\subsection{Factors Associated with Institutional Delivery Service Utilization}

The factors that were found to be associated with institutional delivery were residential place, educational level of mothers and husbands, ANC follow up and being birth prepared and ready for its complication. Urban mothers were 3.6 times more likely to deliver at health institutions than rural mothers $(\mathrm{AOR}=3.6$ and $95 \% \mathrm{CI}=1.86$, 7.13).

As compared to those who were not able to read and write, mothers with secondary education and above were 3.1 times more likely to deliver on health facilities $(\mathrm{AOR}=3.1$ and $95 \% \mathrm{CI}=1.41,6.82)$. Regarding the educational status of husbands, mothers whose husband attended secondary school and above were 2.7 times $(\mathrm{AOR}=2.7$ and $95 \% \mathrm{CI}=1.19,6.24)$ more likely to deliver on health institutions as compared to mothers whose husbands were unable to read and write. ANC follow up were also found to be a strong predictor of institutional delivery service utilization. Mothers who visited health facilities for ANC during pregnancy were 2.7 times $(\mathrm{AOR}=2.7$ and $95 \% \mathrm{CI}=1.42,5.24)$ more likely to deliver at health institutions than those who did not visit ANC during the last pregnancy (Table 4).

One of FGD participants from rural kebele who did not attend any education said that, "... for a mother who deliver on health facility, health professionals do not allow even her husband to inter the delivery room who is very close and can share her mystery. However, all of the workers in the hospital; be it a staff or other, come and visit her. This will make even normal birth to be complicated because a mother stops to push it down as a result of the shame she fell."

Table 3. Respondents place of delivery preference, reasons for preference, decision makers for obstetric care service utilization in Goba Woreda, Oromia region, South-East Ethiopia, April 2013.

\begin{tabular}{|c|c|c|}
\hline Variable & Frequency & Percent \\
\hline \multicolumn{3}{|l|}{ Place of last 12 month delivery } \\
\hline Home & 298 & 53 \\
\hline Health facility & 264 & 47 \\
\hline \multicolumn{3}{|l|}{ Why did you prefer to deliver at home* } \\
\hline Too much cost of HFs & 4 & 1.3 \\
\hline Facility too far & 11 & 3.7 \\
\hline Poor quality service of HFs & 1 & 0.3 \\
\hline No female provider at HFs & 2 & 0.7 \\
\hline Husband will not allow & 3 & 1 \\
\hline Need to be with relatives & 13 & 4.4 \\
\hline Presence of TBAs & 48 & 16.1 \\
\hline Labor was smooth and short & 250 & 83.9 \\
\hline Previous home delivery was normal & 111 & 37.2 \\
\hline Lack of accompanies & 4 & 1.3 \\
\hline I was told my pregnancy is normal & 32 & 10.7 \\
\hline Lack of transport & 5 & 1.7 \\
\hline \multicolumn{3}{|c|}{ Why did you prefer to deliver in health facilities* } \\
\hline HF was near to me & 66 & 25.1 \\
\hline Need better service & 211 & 80.2 \\
\hline $\begin{array}{l}\text { Previous better outcome with delivering at } \\
\text { HF }\end{array}$ & 63 & 24 \\
\hline I was told to deliver at health facilities & 95 & 36.1 \\
\hline Difficult labor & 38 & 14.4 \\
\hline Bad outcome with previous delivery & 22 & 8.4 \\
\hline \multicolumn{3}{|l|}{ Travel time to health facility } \\
\hline$<15$ minute & 185 & 32.9 \\
\hline $15-30$ minute & 142 & 25.3 \\
\hline$>30$ minute & 235 & 41.8 \\
\hline \multicolumn{3}{|c|}{$\begin{array}{l}\text { Decision maker for health service seeking during pregnancy, } \\
\text { delivery and postpartum period }\end{array}$} \\
\hline Self & 146 & 26 \\
\hline Husband & 69 & 12.3 \\
\hline Self and Husband jointly & 345 & 61.3 \\
\hline Other & 2 & 0.4 \\
\hline
\end{tabular}

* indicate more than one answer were possible so that cannot be sum up to hundred percent. TBA- traditional birth attendants, HFs- health facilities 
Table 4. Bivariate and multivariate analysis of factors associated with institutional delivery service utilization in Goba Woreda, Oromia region, SouthEast Ethiopia, April, 2013.

\begin{tabular}{|c|c|c|c|c|}
\hline \multirow{2}{*}{ Variables } & \multicolumn{2}{|c|}{ Institutional delivery } & \multirow{2}{*}{$\operatorname{COR}(95 \% \mathrm{CI})$} & \multirow{2}{*}{ AOR $(95 \% C I)$} \\
\hline & No $(\%)$ & Yes (\%) & & \\
\hline \multicolumn{5}{|l|}{ Residence } \\
\hline Urban & $20(17.2)$ & $96(82.8)$ & $7.9(4.73,13.33)$ & $3.6(1.86,7.13)$ \\
\hline Rural & $278(62.3)$ & $168(37.7)$ & 1 & 1 \\
\hline \multicolumn{5}{|l|}{ Marital status } \\
\hline In marital union & $283(53.3)$ & $284(46.7)$ & $0.8(0.39,1.69)$ & \\
\hline Not in marital union & $15(48.4)$ & $16(51.6)$ & 1 & \\
\hline \multicolumn{5}{|l|}{ Educational level } \\
\hline Cannot read and write & $119(73.9)$ & $42(43.8)$ & 1 & 1 \\
\hline Read and write & $9(56.2)$ & $7(43.8)$ & $2.2(0.77,6.28)$ & $0.8(0.24,3.05)$ \\
\hline Primary & $145(54.5)$ & $121(45.5)$ & $2.3(1.54,3.62)$ & $1.4(0.83,2.42)$ \\
\hline Secondary and above & $25(21)$ & 94(79) & $10.6(6.06,18.72)$ & $3.1(1.41,6.82)$ \\
\hline \multicolumn{5}{|c|}{ Educational status of husband } \\
\hline Cannot read and write & $66(79.5)$ & $17(20.5)$ & 1 & 1 \\
\hline Read and write & $21(67.7)$ & $10(32.3)$ & $1.8(0.73,4.65)$ & $2.1(0.76,6.10)$ \\
\hline Primary & $160(59)$ & $111(41.0)$ & $2.6(1.50,4.83)$ & $1.42(0.73,2.78)$ \\
\hline Secondary and above & $41(25.8)$ & $118(74.2)$ & $11.1(5.88,21.20)$ & $2.7(1.19,6.24)$ \\
\hline \multicolumn{5}{|l|}{ Occupation of mother } \\
\hline House wife & $271(56.6)$ & $208(43.2)$ & 1 & 1 \\
\hline Government & $5(23.8)$ & $16(76.2)$ & $4.1(1.50,11.56)$ & $0.5(0.14,2.11)$ \\
\hline Employee & $4(28.6)$ & $10(71.4)$ & $3.2(1.00,10.53)$ & $1.47(0.35,6.16)$ \\
\hline Merchants & $16(38.1)$ & $26(61.9)$ & $2.1(1.10,4.04)$ & $0.7(0.30,1.66)$ \\
\hline Others & $2(33.3)$ & $4(66.7)$ & $2.6(0.47,14.36)$ & $0.5(0.01,24.60)$ \\
\hline \multicolumn{5}{|l|}{ Occupation of husband } \\
\hline Farmer & $237(70.5)$ & $99(29.5)$ & 1 & 1 \\
\hline Government Employee & $15(19.7)$ & $61(80.3)$ & $9.7(5.28,17.94)$ & $2.6(1.19,5.81)$ \\
\hline Private Employee & $24(30)$ & $56(70)$ & $5.5(3.27,9.51)$ & $2.9(1.54,5.74)$ \\
\hline Merchants & $12(23.1)$ & $40(76.9)$ & $7.9(4.01,15.85)$ & $4.0(1.82,9.12)$ \\
\hline \multicolumn{5}{|c|}{ Distance from nearest HF } \\
\hline$<15$ minute & $111(60)$ & $74(40)$ & $0.7(0.48,1.06)$ & \\
\hline $15-30$ minute & $65(45.8)$ & $77(54.2)$ & $1.27(0.84,1.94)$ & \\
\hline$>30$ minute & $122(51.9)$ & $113(48.1)$ & 1 & \\
\hline \multicolumn{5}{|c|}{ Decision makers to seek health care } \\
\hline Self & $86(59.8)$ & $60(41.1)$ & $0.6(0.04,11.37)$ & \\
\hline Husband & $42(60.9)$ & $27(39.1)$ & $0.6(0.03,10.71)$ & \\
\hline Jointly & $169(49)$ & $176(51)$ & $1.0(0.06,16.78)$ & \\
\hline 0ther & $1(50)$ & $1(50)$ & 1 & \\
\hline \multicolumn{5}{|l|}{ ANC follow up } \\
\hline Yes & $231(48.3)$ & $247(51.7)$ & $4.2(2.40,7.39)$ & $2.7(1.42,5.24)$ \\
\hline No & $67(79.8)$ & $17(20.2)$ & 1 & 1 \\
\hline \multicolumn{5}{|l|}{ Number of ANC visit } \\
\hline$<4$ & $200(50.5)$ & $196(49.5)$ & 1 & \\
\hline$\geq 4$ & $32(39)$ & $50(61.0)$ & $1.5(0.98,2.59)$ & \\
\hline \multicolumn{5}{|l|}{ BPCR } \\
\hline Not prepared & $241(61.2)$ & $153(38.8)$ & 1 & 1 \\
\hline Prepared & $57(33.9)$ & $111(66.1)$ & $3.0(2.10,4.47)$ & $1.7(1.08,2.85)$ \\
\hline \multicolumn{5}{|c|}{ Knowledge status of danger-sign during pregnancy } \\
\hline Not knowledgeable & $215(56.1)$ & $168(43.9)$ & 1 & 1 \\
\hline Knowledgeable & $83(46.4)$ & $96(53.6)$ & $1.4(1.03,2.11)$ & $0.8(0.48,1.45)$ \\
\hline \multicolumn{5}{|c|}{ Knowledge status of danger-sign during labour } \\
\hline Not knowledgeable & $230(56.1)$ & $180(43.9)$ & 1 & 1 \\
\hline Knowledgeable & $68(44.7)$ & $84(55.3)$ & $1.5(1.08,2.29)$ & $0.5(0.32,1.10)$ \\
\hline \multicolumn{5}{|c|}{ Knowledge status of danger-sign during postpartum period } \\
\hline Not Knowledgeable & $244(55.7)$ & 194(44.3) & 1 & 1 \\
\hline knowledgeable & $54(43.5)$ & $70(56.5)$ & $0.6(0.41,0.91)$ & $1.1(0.63,2.10)$ \\
\hline
\end{tabular}




\section{Discussion}

This study is a community based study in randomly selected kebeles. It included both urban and rural settings. The survey was also supplemented by qualitative data collection methods. Skilled attendants are important during pregnancy, child birth and the immediate postnatal period.

Out of 562 mothers who gave birth during the last 12 months prior this survey, $264(47 \%)$ gave birth on health facilities and 298 (53\%) delivered at home. This finding is consistent with other studies conducted in Woldia Woreda, Ethiopia [9], Nyandarua South District, Kenya [14], Enugu, Nigeria [15] and Southern Tanzania [16] where the proportion of women who gave birth on health facilities was $227(48.3 \%), 562(48 \%), 47.1 \%$, and $46.7 \%$, respectively. However, it is higher as compared to similar community based studies conducted in Dodota Woreda [10], Sekela District, [17] and Munisa Woreda, South East Ethiopia [8], where the proportion of women who gave birth at health facilities was, only $18 \%, 12.3 \%, 12.1 \%$ respectively. This discrepancy could be due to the time gap between these studies, difference in study settings and there might have been improvements in accessibility and utilization of health institution delivery service.

The likelihood of giving birth in health institutions depends on many factors, including place of residence, mother's demographic and socioeconomic characteristics, and availability and quality of health services [18]. These factors were also associated with institutional delivery service utilization in this study. On multivariable logistic regression analysis, occupational status of the mother, educational status of the mother, residence, ANC follow up , husband's educational status, husband's occupational status and birth preparedness and complication readiness were the factors that have statistically significant association with institutional delivery service utilization.

Mothers who lived in Urban Kebele were about four times more likely to deliver in health facilities than those who live in Rural Kebeles. This finding was nearly consistent with other studies conducted in different parts of Ethiopia at different time $[9,10,17]$. The possible explanation for this finding could be due to the presence of higher proportion of educated mothers in urban settings as compared to rural settings. In addition to this, mothers in urban area could be autonomous in making decision, have good knowledge of pregnancy and delivery complications, and better access to information than rural mothers. One of the urban kebele Focus Group discussants expresses her idea for health institution preference for delivery service as follow; "If you take the rural community, most of the mothers prefer to deliver at home because of many cultural reasons and fear of cold when they deliver at health facilities. In our case, we are living in the town and have awareness on institutional delivery".

Another FGD participant from rural kebele with no formal education justified her reason to give birth at home;
"I have question for you; if the labor is prolonged, it is good to take a mother to health facilities. However, what is the value of taking normal mother when she can deliver normally in her home? Everywhere there is God; why not at hospital; health professionals working in health center can do nothing for us unless the God leave his mercy for us".

This study showed that mothers who had ANC visits during the last pregnancy were about three times more likely to deliver at health facilities compared to those who did not have any visit. It is consistent with other studies [8, 19, 20]. ANC services can provide opportunities for health workers to promote a specific place of delivery or give women information on the status of their pregnancy which in turn alerts them to decide where to deliver. This condition was reflected from Focus Group Discussion participants; "When I visited the nearby health center for check up, the position of the baby in my womb was identified as it was not on the right position so that health professionals told me to give birth in health institution and I did so".

Mothers who had educational level of secondary and above were about 3 times more likely to utilize institutional delivery service than mothers who cannot read and write. This finding is consistent with previous studies which showed educational status of mothers to be the most significant associated factors for utilization of institutional delivery service [9]. Similarly, husbands' educational level was also one of the factors that predicted health institution delivery. Women whose husbands had secondary and above education were about 2.7 times more likely to deliver in health facilities as compared to those whose husbands were unable to read and write. Our finding was in line with that of a study done in Munisa Woreda, South East Ethiopia [8]. The possible explanation for this might be that educated husbands could be more open toward modern medicine and aware of the benefits of giving birth at health facilities. They might also put fewer constraints on their wives' mobility and decision making, thus facilitate care-seeking behavior.

One of grade twelve complete urban kebele FGD participants justified her preference for institutional delivery as follow; "I prefer hospital because if I give birth in the home, the labor may be long and the baby might be asphyxiated. However, in the hospital even if this thing happens, there will be help from health professionals. In addition to this, when delivery is in health facilities, vaccination will be given immediately for a baby but it is impossible for a baby born at home".

\section{Conclusion}

This study revealed that the proportion of women who gave birth at health facilities in the woreda seem higher as compared to some of the studies conducted on different parts of the country and with national Demographic and 
Health Survey of 2012. However, still it needs strong effort to meet the required level of skilled birth attendant which is 100 percent. Urban residence, ANC visit during pregnancy, secondary and above levels of education of mothers and husbands were factors significantly associated with institutional delivery service utilization. Increasing awareness of mothers and their partners about the benefits of institutional delivery services are recommended. Health education for mothers about benefits of institutional delivery service utilization and risks of home delivery should also be given due attention during ANC follow up by health professionals to increase institutional delivery service utilization.

\section{Acknowledgements}

Funding for this study was made possible through grants offered by Madawalabu University. The authors are grateful to the respondents who offered their time to participate in this study. Special thanks go to the research assistants who participated in data collection.

\section{References}

[1] World Health Organization: Trends in Maternal Mortality: 1990 to 2010 Estimates developed by WHO, UNICEF, UNFPA and The World Bank. Geneva; 2012.

[2] Kamal S.M.M: Preference for Institutional Delivery and Caesarean Sections in Bangladesh. J Health Popul Nutr 2013; 31(1): 96-109.

[3] MC Hogan, KJ Foreman, M Naghavi, SY Ahn, M Wang, SM Makela, AD Lopez, R Lozano, CJ Murray: Maternal mortality for 181 countries, 1980-2008: a systematic analysis of progress towards Millennium Development Goal 5. Lancet 2010; 375(9726):1609-23.

[4] FMOH, UNICEF, UNFPA, WHO and AMDD: National Baseline Assessment for Emergency Obstetric and Newborn Care in Ethiopia; 2008:18.

[5] Central Statistical Agency [Ethiopia] and ORC Macro: Ethiopia Demographic and Health Survey 2005: Addis Ababa. Central Statistical Agency and ORC Macro; 2005.

[6] Central Statistical Agency (Ethiopia) and ICF International: Ethiopian Demographic and Health Survey: Addis Ababa. Ethiopia, Calverton, Maryland and USA; 2012.

[7] Abebe F, Berhane Y, and Girma B: Factors associated with home delivery in Bahirdar, Ethiopia: A case control study. BMC Research Notes, 2012; 5: p. 653.

[8] Amano A, Gebeyehu A, and Birhanu Z: Institutional delivery service utilization in Munisa Woreda, South East
Ethiopia: a community based cross-sectional study. BMC Pregnancy and Childbirth, 2012; 12: p. 105.

[9] Awoke W, Muhammed J, and Abeje G: Institutional delivery service utilization in Woldia. Ethiopia Science Journal of Public Health, 2013; 1(1): 18-23 doi: 10.11648/j.sjph.20130101.13.

[10] Fikre and Demissie: Prevalence of institutional delivery and associated factors in Dodota Woreda, Oromia regional state, Ethiopia. Reproductive Health, 2012; 9: p. 33.

[11] Sugathan K.S, Mishra V and Retherford R.D: Promoting Institutional Deliveries In Rural India: The Role of Antenatal-Care Services. National Family Health Survey Subject Reports, 2001; 20.

[12] Nigatu D: Women's autonomy regarding their own and children's Health care utilization and associated factors in Goba Woreda, Bale zone, south east Ethiopia, in Public health institutions. Addis Ababa, 2011.

[13] JHPIEGO: Monitoring birth preparedness and complication readiness: tools and Indicators for maternal and newborn health. JHPIEGO; 2004.

[14] Wanjira C, Mwangi M, Mathenge E, Mbugua G and Ng'ang'a Z: Delivery Practices and Associated Factors among Mothers Seeking Child Welfare Services in Selected Health Facilities in Nyandarua South District, Kenya. BMC Public Health, 2011: 11(360).

[15] Onah HE, Ikeako LC, Iloabachie GC: Factors associated with the use of maternity services in Enugu, south-eastern Nigeria. Soc Sci Med, 2006; 63(7): 1870-1878.

[16] Mpembeni RNM, Killewo JZ, Leshabari MT, et al: Use pattern of maternal health services and determinants of skilled care during delivery in Southern Tanzania: implications for achievement of MDG-5 targets. BMC Pregnancy and Childbirth, 2007: 7(29).

[17] Teferra A.S, Alemu F.M, and Woldeyohannes S.M: Institutional delivery service utilization and associated factors among mothers who gave birth in the last 12 months in Sekela District, North West of Ethiopia: A community based cross sectional study. BMC Pregnancy and Childbirth, 2012: 12(74).

[18] Sugathan K.S, Mishra V, and Retherford R.D: Promoting Institutional Deliveries In Rural India: The Role of Antenatal-Care Services, in National Family Health Survey Subject Reports. 2001, International Institute for Population Sciences: Mumbai, India.

[19] Nigussie M, HaileMariam D and Mitike G: Assessment of safe delivery service utilization among women of childbearing age in north Gondar Zone, North West Ethiopia. Ethiop J Health Dev, 2004: 18(3): 145-152.

[20] Gage A.J: Barriers to the utilization of maternal health care in rural Mali. Soc Sci Med, 2007: 65(8): 1666-1682. 